Tropical Journal of Pharmaceutical Research April 2017; 16 (4): 939-945

ISSN: $1596-5996$ (print); 1596-9827 (electronic)

(C) Pharmacotherapy Group, Faculty of Pharmacy, University of Benin, Benin City, 300001 Nigeria.

All rights reserved.

Available online at http://www.tjpr.org

Original Research Article

http://dx.doi.org/10.4314/tjpr.v16i4.28

\title{
Adverse drug reaction in HIV-infected people treated with HAART in Maringá, Southern Brazil
}

\author{
lone Takaki ${ }^{1}$, Luciana Quirelli ${ }^{2}$ and Roberto KN Cuman ${ }^{2 \star}$ \\ ${ }^{1}$ Department of Clinical Analysis and Biomedicine, ${ }^{2}$ Department of Pharmacology and Therapeutics, State University of \\ Maringá, Paraná, Brazil \\ *For correspondence: Email: rkncuman1@gmail.com; Tel: + 554430114867
}

Received: 17 August 2016

Revised accepted: 11 March 2017

\begin{abstract}
Purpose: To assess the knowledge of adverse drug reactions (ADRs) among HIV-infected patients on prolonged treatment with highly active antiretroviral therapy (HAART) at a public health facility in Maringá, Southern Brazil.

Methods: $A$ retrospective and prospective analysis of laboratory results and clinical epidemiological characteristics was conducted among 220 HIV-infected patients treated with HAART between January 2010 and December 2013, at a public health care and treatment center in Maringá, Southern Brazil. The immunological and virological profiles of participants were evaluated.

Results: The mean age of antiretroviral therapy (ART) participants was $44.3 \pm 10.8$ years and there was no substantial age difference between males and females. The mean of the first and last CD4+ $T$ count were $550 \pm 309 \mathrm{cells} / \mu \mathrm{L}$ and $642 \pm 372 \mathrm{cells} / \mu \mathrm{L}$, respectively. Similarly, the first and last mean viral load were 14,476 $\pm 58,067$ copies $/ \mathrm{mL}$ and 20,828 $\pm 106,028$ copies $/ \mathrm{mL}$, respectively. The therapeutic regimen was either two nucleoside reverse transcriptase inhibitors (NRTIs) and one protease inhibitor (PI) in $102(46.4 \%)$ patients, or two NRTIs and one non-nucleoside reverse inhibitor (NNRTI) in 79 (35.9 \%). Gastrointestinal disorders (25.9\%), hypertension (25.4 \%), and neuropsychiatric symptoms (18.2\%) were the most common clinical ADRs. The most common laboratory-based ADRs were anemia (48.8\%), hypertriglyceridemia (47.3\%), hypercholesterolemia (36.1\%) and hyperglycemia (22.6\%).

Conclusion: The results demonstrate a high incidence of ADRs in HIV-patients treated with HAART, which should be monitored closely during follow-up therapy.
\end{abstract}

Keywords: HIV, AIDS, Highly active antiretroviral therapy (HAART), Adverse drug reaction

Tropical Journal of Pharmaceutical Research is indexed by Science Citation Index (SciSearch), Scopus, International Pharmaceutical Abstract, Chemical Abstracts, Embase, Index Copernicus, EBSCO, African Index Medicus, JournalSeek, Journal Citation Reports/Science Edition, Directory of Open Access Journals (DOAJ), African Journal Online, Bioline International, Open-J-Gate and Pharmacy Abstracts

\section{INTRODUCTION}

The introduction of highly active antiretroviral therapy (HAART) has led to a significant reduction in autoimmune deficiency syndrome (AIDS)-related morbidity and mortality [1]. However, an increase in the number of adverse drug reactions (ADRs) has accompanied these beneficial effects. ADRs play a major role in determining adherence to HAART and adherence is perhaps the most significant determinant of a regimen's success. ADRs are also becoming increasingly important in our effort to diminish toxicities that can, along with the human immunodeficiency virus (HIV) itself and the increasing age of patients living with HIV contribute to an increase in the prevalence of chronic diseases of aging in the HIV-positive population [2].

The development of new antiretroviral (ARV) agents has been performed to improve the 
duration and effectiveness of the treatment, and a better understanding and manage of ADRs. Thus, each ARV drug is associated with its own specific ADRs which could occur in a particular clinical circumstance. The risk of specific side effects varies from drug to drug, from drug class to drug class, and from patient to patient [3].

The ADR is a critical component of HIV/AIDS care and treatment, whereas it should be evaluated the prevalence, pathogenesis of ADRs to inform clinical management. A better understanding of ADRs occurred in HIV-patients could help specialists to optimize therapy, and also to improve the care for HIV-positive patients.

\section{METHODS}

\section{Study design and study population}

A retrospective and prospective analysis was conducted of the clinical epidemiological characteristics and laboratory results noted in the medical records of $220 \mathrm{HIV}$-infected patients treated with HAART between January 2010 and December 2013, at a public health center for care and treatment in Maringá, Southern Brazil.

\section{Inclusion and exclusion criteria}

The inclusion criteria were HIV-infected patients receiving HAART. Exclusion criteria were aged less 18 years and pregnant women.

\section{Data collection}

The following laboratory results and clinicepidemiological characteristics were collected: sex, age, type and class of HAART, clinical data, plasma viral load, CD4+ T cell count, and standard laboratory determinations of red blood cell, and platelets counts as well as cholesterol, triglyceride, glucose, aspartate and alanine aminotranferases and creatinine levels. Clinical data included the blood pressure, clinical ADRs, failure to adhere to the medication regimen and opportunistic diseases.

\section{Definition of laboratory-based adverse drug reactions}

Laboratory findings were considered to represent ADRs when they were abnormal on at least two determinations after starting HAART.

\section{Data analysis}

Data are expressed as mean \pm standard error of the mean for continuous variables and as the number of subjects and percentages for categorical variables. Patients were stratified by sex and type of HAART. The Excel Program and GraphPad Prism version 5.01 were used to analyze the data. The covariates considered in the analysis were age, sex, clinics and ARV medication regimens.

\section{Ethical considerations}

Written informed consent was obtained from each patient for the publication of this research and any accompanying images. We obtained ethics approval for our study from the ethics committee of the State University of Maringá, Brazil (CAAE $n^{\circ}$. 00042.0.93.000-11, Parecer $\left.\mathrm{n}^{\circ} .097 / 2011\right)$. All procedures used in the study were in accordance with current international guidelines, including standards for on human experimentation of the Ethics Committee of the State University of Maringá, Brazil, and the Helsinki Declaration of 1975, revised in 1983.

\section{RESULTS}

\section{Characteristics of participants}

In total, 220 HIV-infected people receiving HAART were included in this study, of which 110 (50\%) were females and 110 (50\%) were males. The mean age of the participants was $44.3 \pm 10.8$ years; the mean ages was similar for males and females. The number of married participants was 84 (38.2\%), of which 39 (46.4 $\%)$ were females and 45 (53.6 \%) were males. The marital status was not indicated in the chart in $59(26.8 \%)$ participants.

\section{HIV information}

The immunological and virological profiles of participants showed that the means of the first and last CD4+ T counts were $550 \pm 309$ cells $/ \mu \mathrm{L}$ and $642 \pm 372$ cells $/ \mu \mathrm{L}$, respectively. Similarly, the first and the last mean viral loads were $14,476 \pm 58,067$ copies $/ \mathrm{mL}$ and 20,828 \pm 106,028 copies/mL, respectively (Table 1 ).

The mean duration of ARV medication use was $5.6 \pm 4.2$ years for all participants, $6.0 \pm 4.2$ years for females and $5.4 \pm 4.3$ years for males (Table 1). In total, 28 (12.8\%) participants reported failing to adhere to their medications some time during the years of this study (Table 1).

\section{Therapeutic regimens}

In 102 (46.4\%) patients the therapeutic regimen was based on two nucleoside reverse transcriptase inhibitors (NRTIs) and one protease 
inhibitor $(\mathrm{PI})$ : the two most common types of these combination were lamivudine (3TC) zidovudine (AZT) - lopinavir/ritonavir (LPV/r) (31.4 \%), and 3TC-AZT- atazanavir/ritonavir $(\mathrm{ATV} / \mathrm{r})(28.4 \%)$. The therapeutic regimen of two NRTIs and one non-nucleoside reverse transcriptase inhibitors (NNRTI) was used for 79 $(35.9 \%)$ patients: the most common of these combination was 3TC-AZT- efavirenz (EFZ) $(65.8 \%)$. Another regimen was received by 39 (17.7\%) patients (Table 2).

\section{Prevalence of adverse drug reactions}

Gastrointestinal disorders (25.9\%), hypertension (25.4\%), and neuropsychiatric symptoms (18.2 $\%)$ were the most common ADRs in patients during the study period. Overall, the number of patients with hypertension was 56 (25.4 \%); hypertension was more common in males $(64.3$ $\%)$ than in females (35.7\%), Overall, 38 (17.3\%) had an opportunistic disease, and 11 (5.0\%) developed lipodystrophy (Table 1).
Patients were included in the analyses of laboratory-based ADRs if they underwent at least one annual clinical examination and at least two laboratory tests. If at least two of laboratory test results were outside the reference value, the patient was considered to have an ADR (Table 3). The most common laboratory-based ADRs were: anemia (48.8 \%), hypertriglyceridemia (47.3\%), hypercholesterolemia (36.1\%) and hyperglycemia (22.6\%).

\section{DISCUSSION}

HAART is the gold standard for HIV/AIDS treatment, which is demonstrated by the benefits on disease progression, immune reconstitution and mortality. Furthermore, commonly these advantages are accompanied by a significant increase in the number of ADRs.

The occurrence of ADRs may negatively affect the quality of life of patients as well as adherence to the treatment. The spectrum of adverse events is wide and varied, being difficult to identify the principal cause [4].

Table 1: HIV information and clinical ADRs

\begin{tabular}{|c|c|c|c|}
\hline Variable & $\begin{array}{c}\text { All participants } \\
N=220\end{array}$ & $\begin{array}{c}\text { Females } \\
\mathrm{N}=110\end{array}$ & $\begin{array}{c}\text { Males } \\
\mathrm{N}=110\end{array}$ \\
\hline \multicolumn{4}{|l|}{ HIV information } \\
\hline CD4 count (cells/uL) (1st) & $550 \pm 309$ & $578 \pm 322$ & $521 \pm 293$ \\
\hline CD4 count (cells/uL) (last) & $642 \pm 372$ & $658 \pm 393$ & $626 \pm 350$ \\
\hline Viral load (copies/mL) (1st) & $14,476 \pm 58,067$ & $11,995 \pm 61,342$ & $17,002 \pm 54,703$ \\
\hline Viral load (copies/mL) (last) & $20,828 \pm 106,028$ & $23,585 \pm 117,037$ & $18,020 \pm 93,968$ \\
\hline ART duration (years) & $5.6 \pm 4.2$ & $6 \pm 4.2$ & $5.4 \pm 4.3$ \\
\hline Medication adherence failure & $28(12.8)^{\mathrm{a}}$ & $15(53.6)^{a}$ & $13(46.4)^{\mathrm{a}}$ \\
\hline \multicolumn{4}{|l|}{$A D R$} \\
\hline Gastrointestinal disorders & $57(25.9)^{\mathrm{D}}$ & $35(61.4)$ & $22(38.6)$ \\
\hline Sleep disorders & $19(8.6)$ & $14(73.6)$ & $5(26.6)$ \\
\hline Neuropsychiatric symptoms & $40(18.2)$ & $26(23.6)$ & $14(12.7)$ \\
\hline Paresthesia & $17(7.7)$ & $10(58.8)$ & $7(41.2)$ \\
\hline Headache & $19(8.6)$ & $14(76.8)$ & $5(26.3)$ \\
\hline Asthenia & 29 (13.2) & $18(62.1)$ & $11(37.9)$ \\
\hline Lipodystrophy & $11(5.0)$ & $7(63.6)$ & $4(36.4)$ \\
\hline Hypertension & $56(25.4)$ & $20(35.7)$ & $36(64.3)$ \\
\hline Others & $9(4.1)$ & $6(66.6)$ & $2(33.3)$ \\
\hline Opportunistic diseases & $38(17.3)$ & $17(44.7)$ & $21(55.3)$ \\
\hline
\end{tabular}

Data are mean \pm standard error of the mean or number (\%). ${ }^{a}$ This percentage represents the percentage of patients with medication adherence failure. ${ }^{\mathrm{b}}$ The percentages in these columns represent the percentage of all patients with the specific adverse drug reactions. Hypertension- systolic blood pressure $>140$ and/or diastolic pressure $>90$. HIV (human immunodeficiency virus), ART (antiretroviral therapy), ADR (adverse drug reactions)

Table 2: Therapeutic regimens

\begin{tabular}{lccc}
\hline & 2 NRTI plus 1 PI (N= 102) & \multicolumn{2}{c}{ 2 NRTI plus 1 NNRTI (N= 79) } \\
\hline & $\mathbf{N}(\%)$ & & $\mathbf{N}(\%)$ \\
\hline 3TC - AZT - LPV/r & $32(31.4)$ & 3TC - AZT - EFZ & $52(65.8)$ \\
3TC - AZT - ATV/r & $29(28.4)$ & 3TC - EFZ - TDF & $9(11.4)$ \\
3TC - TDF - ATV/r & $13(12.7)$ & 3TC - AZT - NVP & $7(8.9)$ \\
3TC - TDF - LPV/r & $13(12.7)$ & Others combinations & $11(13.9)$ \\
\hline Others combinations & $15(14.7)$ & & \\
\hline
\end{tabular}

Data are number (\%). NRTI (nucleoside reverse transcriptase inhibitors), NNRTI (non-nucleoside reverse transcriptase inhibitors), PI (proteases), 3TC (lamivudine), AZT (zidovudine), LPV/r (lopinavir/ritonavir), ATV/r (atazanavir/ritonavir), TDF (tenofovir), EFZ (efavirenz), NVP (nevirapine) 
Table 3: Prevalence of laboratory-based adverse drug reactions

\begin{tabular}{|c|c|c|c|c|c|c|c|c|}
\hline & \multicolumn{2}{|c|}{ ADR } & \multicolumn{4}{|c|}{ Treatment } & \multicolumn{2}{|c|}{ Gender } \\
\hline & NO (\%) & YES (\%) & $\begin{array}{c}2 \text { NTRI } \\
1 \text { NNRTI (\%) }\end{array}$ & $\begin{array}{c}2 \text { NRTI } 1 \text { PI } \\
(\%)\end{array}$ & $\begin{array}{c}\text { Others } \\
\text { combinations } \\
(\%)\end{array}$ & $\begin{array}{l}\text { Without } \\
\text { ARV (\%) }\end{array}$ & Females (\%) & Males (\%) \\
\hline Anemia & $87(51.7)$ & $83(48.2)$ & $32(38.5)$ & $43(51.8)$ & $8(9.6)$ & & $59(71.1)$ & $24(28.9)$ \\
\hline Thrombocytopenia & $158(94.6)$ & $9(5.4)$ & $1(11.1)$ & $6(66.6)$ & $2(22.2)$ & & $5(55.5)$ & $4(44.5)$ \\
\hline Hypercholesterolemia & $108(63.9)$ & $61(36.1)$ & $22(36.1)$ & $21(34.4)$ & $17(27.9)$ & $1(1.6)$ & $30(49.2)$ & $31(50.8)$ \\
\hline Hypertriglyceridemia & $89(52.7)$ & $80(47.3)$ & $25(31.2)$ & $35(43.7)$ & $18(22.5)$ & $2(2.5)$ & $34(42.5)$ & $46(57.5)$ \\
\hline Hyperglycemia & $130(77.4)$ & $38(22.6)$ & $11(28.9)$ & $18(47.3)$ & $7(18.4)$ & $2(5.3)$ & $16(42.1)$ & $22(57.9)$ \\
\hline $\begin{array}{l}\text { Aspartate } \\
\text { aminotransferase }\end{array}$ & $154(92.2)$ & $13(7,8)$ & $5(38.4)$ & $6(46.1)$ & & $2(15.4)$ & $5(38.5)$ & $8(61.5)$ \\
\hline Alanine aminotransferase & $152(91.6)$ & $14(8.4)$ & $9(64.3)$ & $3(21.4)$ & $1(7.1)$ & $1(7.1)$ & $5(35.7)$ & $9(64.3)$ \\
\hline Creatinine & $142(94.1)$ & $9(5.9)$ & $2(22.2)$ & $3(33.3)$ & $4(44.4)$ & & $5(55.5)$ & $4(44.5)$ \\
\hline
\end{tabular}

Data are number (\%). ADR, adverse drug reaction; NRTI nucleoside reverse transcriptase inhibitors, NNRTI non-nucleoside reverse transcriptase inhibitors,

PI proteases inhibitors, ARV antiretroviral 
Our study showed that the most common ADRs were related to gastrointestinal effects, and neuropsychiatric symptoms, being mild, occurring early during the course of most HAART, and may be transient or persist throughout therapy [3].

The prevalence of anemia is higher in the HIVinfected population, particularly among individuals with AIDS [5,6]. Some of ARV drugs, such as AZT are myelosuppressive, and affect red blood cells, and therefore lead to anemia, a common manifestation of HIV infection both before and after the treatment initiation [7]. Anemia was present in $48.8 \%$ of our patients in whom this parameter was evaluated. HAART is effective in reducing anemia by inhibiting the progress of disease [8]. AZT used in many therapeutic regimens in our patients, has been associated with hematological toxicity $[9,10]$.

A large number of patients exhibited abnormal glycemic and lipid profiles with all classes of ARV agents, despite the relatively young age of our study population. The hyperlipidemia has been associated with the use of HIV PIs, which is more common and more severe than hyperlipidemia observed in HAART naïve $[11,12]$.

Nevertheless, prolonged use of HAART, including PIs, is necessary to control HIV infection [13]. Hyperlipidemia, and hyperglycemia (reflecting Insulin resistance) and lipodystrophy are increasingly described ADRs of PIs [14,15]. Furthermore, the NRTIs, especially stavudine (d4T) has been associated with lipodystrophy [16].

In our patients, $5 \%$ had lipodystrophy. Lipodystrophy is characterized by changes in body fat distribution including increased waist circumference, increased breast size, and, fat accumulation in the neck, cheeks, and buttocks. Hyperlipidemia/dyslipidemia, hyperglycemia, and lipodystrophy are cardiovascular risk factors in people with HIV infection treated with HAART [17-19].

In our study, many patients exhibited changes in blood pressure. Hypertension is associated with established risk factors, and is common among HIV-infected individuals. The high prevalence of hypertension has been associated with duration of HIV infection, whereas virally-mediated endothelial changes or immune activations may play a role [20].

Our study also found that HIV-infected females had a significantly higher risk of experiencing an
ADR than males. This is consistent with research conducted in Ethiopia and Ghana [21,4]. In contrast to these findings, a study in HIV infected patients at an ART Centre of tertiary care hospital in India showed a higher prevalence in males than in females [22]. The sex difference in ADRs might be explained by differences in body mass index and fat composition between men and women, and also, hormonal effects on drug metabolism, or constitutional genetic differences.

At the beginning of the ARV treatment, HIVinfected patients can frequently exhibit a wide variety of ADRs such as rashes, hair loss, hypersensitivity reactions, urticaria, or erythema multiform. Further, it has been reported that up to $80 \%$ of HIV -infected patients experience ADRs during their therapy, presumably as a result of immune dysregulation, altered drug metabolism and/or drug interactions [21].

Monitoring safety and toxicity related to HAART remains a challenge facing the public health sector. Monitoring is usually performed using spontaneous surveillance of HIV patients receiving treatment. Spontaneous reporting of ADRs is a very inefficient system for detecting drug-related conditions, leading to underestimation of the true burden caused by ADRs.

This study has limitations. It was performed in a single care center, excluding a large number of HIV-infected patients who were receiving HAART. Given the variability of ARV agents and therapeutic regimens used and the difficulty of the potential predictors of ADRs, there may be a limitation of interpretability of the findings in the study, without being able to lead to a definitive conclusions.

\section{CONCLUSION}

In spite of HAART effectiveness in control of HIVdisease, many ADRs are evident in the study population, whereas antiretroviral therapy failure is due to patient non-adherence. With early HIV detection, early ARV initiation, increased lifespan of infected individuals (due to HAART), the length of ARV exposure and burden of related metabolic complications are also expected to rise.

The findings on ADRs may require switching of therapy, and should afford valuable information to physicians and concerned organizations, including health care facilities, on when there is need to modify HAART regimens. 


\section{DECLARATIONS}

\section{Acknowledgement}

This research was not supported by a specific grant from any funding agency in the public, commercial, or not-for-profit sectors

\section{Conflict of Interest}

No conflict of interest associated with this work.

\section{Contribution of Authors}

The authors declare that this work was done by the authors named in this article and all liabilities pertaining to claims relating to the content of this article will be borne by them.

\section{Open Access}

This is an Open Access article that uses a funding model which does not charge readers or their institutions for access and distributed under the terms of the Creative Commons Attribution License (http://creativecommons.org/licenses/by/ 4.0) and the Budapest Open Access Initiative (http://www.budapestopenaccessinitiative.org/rea d), which permit unrestricted use, distribution, and reproduction in any medium, provided the original work is properly credited.

\section{REFERENCES}

1. Palella FJ, Delaney KM, Moorman AC, Loveless $M O$, Fuhrer J, Satten GA, Aschman DJ, Holmberg SD, Von Bargen JC, Gardner $C$ et al. Declining morbidity and mortality among patients with advanced human immunodeficiency virus infections. N Engl J Med. 1998; 338(13): 853-860.

2. Hawkins $T$. Understanding and managing the adverse effects of antiretroviral therapy. Anti Res. 2010; 85: 201209.

3. Montessori V, Press N, Harris M, Akagi L, Montaner JSG. Adverse effects of antiretroviral therapy for HIV infection. CMAJ. 2004; 170: 229-238.

4. Lartey M, Asante-Quashie A, Esses A, Kenu E, Ganu V, Neequaye $A$. Adverse drug reactions to antiretroviral therapy during the early art period at terciary hospital in Ghana. Pan Afr Med J. 2014, 18:25. doi:10.11604/pamj.2014.18.25.3886.

5. Miles SA. Hematopoietic growth factors as adjuncts to antiretroviral therapy. AIDS Res Hum Retroviruses. 2009; 8(6): 1073-1080.

6. Sullivan PS, Hanson DL, Chu SY, Jones JL, Ward JW, Burkham S, Buskin S, Davidson A, McNaughten AD, Reynolds K.. Epidemiology of anemia in human immunodeficiency virus (HIV)-infected person: Results from the multistate adult and adolescent spectrum of
HIV Disease Surveillance Project. Blood. 1998; 91: $301-$ 308.

7. Assefa M, Abegaz WE, Shewamare A, Medhin G, Belay M. Prevalence and correlates of anemia among HIV infected patients on highly active anti-retroviral therapy at Zewditu Memorial Hospital, Ethiopia. BMC Hematology. 2015; 15:6. doi 10.1186/s12878-015-00246.

8. Moore RD, Forney D. Anemia in HIV-infected patients receiving highly active antiretroviral therapy. J Acquir Immune Defic Syndr. 2002; 29 (1): 54-57.

9. Groopman JE. Zidovudine Intolerance. Clin Infect Dis. 1990; 12(sup/ 5): 500-506.

10. Cunkendall SM, Richardson JT, Emons MF, Fisher AE, Everhard F. Incidence of anaemia among HIV-infected patients treated with highly active antiretroviral therapy. HIV Medicine. 2007; 8: 483-490.

11. Ngala RA, Fianko K. Dyslipidemia and dysglycaemia in HIV-infected patients on highly active anti-retroviral therapy in Kumasi Metropolis. Afr Health Sci. 2013; 13(4): 1107-1116.

12. Ali I, Keisam RD, Keisam A, Prasad L, Salam R, Thangjam PS. Metabolic abnormalities and body composition in Human Immunodeficiency Virus-infected patients receiving highly active anti-retroviral therapy. $J$ Med Nutr Nutraceut. 2014; 3(2): 94-98.

13. Egger $M$, HirschelB, Francioli $P$, Sudre $P$, Wirz M, Flepp $M$, Rickenbach $M$, Malinverni $R$, Vernazza $P$, Battegay $M$ and the Swiss HIV Cohort Study. Impact of new antiretroviral combination therapies in HIV infected patients in Switzerland: prospective multicentre study. BMJ. 1997; 315: 1194-1199.

14. Carr A, Samaras K, Burton S, Law M, Freund J, Chisholm DJ, Cooper DA. A syndrome of peripheral lipodystrophy, hyperlipidaemia and insulin resistance in patients receiving HIV protease inhibitors. AIDS. 1998; 12: F51-F58.

15. Carr A, Samaras K, Thorisdottir A, Kaufmann, GR, Chisholm DJ, Cooper DA. Diagnosis, prediction, and natural course of HIV-1 protease-inhibitor-associated lipodystrophy, hyperlipidaemia, and diabetes mellitus: a cohort study. Lancet. 1999; 353: 2093-2099.

16. Saint-Marc T, Partisani M, Poizot-Martin I, Bruno F, Rouviere O, Lang J, Gastaub J, Toraine J . A syndrome of peripheral fat wasting (lipodystrophy) in patients receiving long-term nucleoside analogue therapy. AIDS. 1999; 13: 1659-1667.

17. Mashinya F, Albert M, Van-geertruyden JP, Colebunder R. Assessment of cardiovascular risk factor in people with HIV infection treated with ART in South Africa: a cross sectional study. AIDS Res Ther. 2015; 12-42. doi.10.1186/s 12981-015-0083-6.

18. Finkelstein JL, Gala P, Rochford R, Glesby MJ, Mehta S. HIVIAIDS and lipodystrophy: Implication for clinical management in resource-limited settings. Journal of the International AIDS Soc. 2015; 18: 19033. http://dx.doi.org/10.7448/IAS.18.1.19033. 
19. Pereira VX, Abreu LC, Valenti VE, Raimundo RD, Silva $M H$, Oliveira FR, Salatini R, Roque AL, Blake MT, Dias ES et al. The lipodystrophy syndrome as a risk marker for cardiovascular disease in Patients with HIV/AIDS Treated with HAART. Int Arch Med. 2015; 8: 78. doi: 10.3823/1677.

20. Medina-Torne S, Ganesan A, Barahona I, Crum-Ciaflone NF. Hypertension is common among HIV-infected persons, but not associated with HAART. JIAPAC. 2012; 11: 20-25.
21. Tatiparthi R, Mamo Y. Prevalence of ADRs and associated factors of antiretroviral treatment on HIV positive adults at Jush. IJOPP.2014; 7 (4): 8-15.

22. Reddy AVK, Lihite RJ, Lahkar M, Choudhury U, Baruah SK. A study on adverse drug reactions in HIV infected patients at a ART Centre of Tertiary Care hospital in Guwajati, India. Asian J Pharm Clin Res. 2013; 6 (2): 102-104. 